\title{
VARIATIONS OF SEA LEVEL AND SEA SURFACE TEMPERATURE IN THE CALDERA OF SANTORINI ISLAND, SOUTHERN AEGEAN SEA
}

\author{
K. Albanakis, and Styllas M. \\ Department of Physical and Environmental Geography, School of Geology, Aristotle University of \\ Thessaloniki, 54124, Thessaloniki, \\ V. Yfantis \\ Department of Geology, School of Geology, Aristotle University of Thessaloniki.
}

\begin{abstract}
Analyses of sea level records within the Caldera of Santorini Island revealed the significance of both oceanographic and atmospheric forcing on the observed signals. Sea level (msl) and sea surface temperature (sst) data were obtained from the four stations of the REMOS monitoring network. Out of the four stations Gialos station is located on the caldera whereas the remaining three (Erinia, Taxiarhis and Agios Nikolaos) are located on the young volcanic islands of Palaia and Nea Kameni. The record of sea level data contained a number of gaps. When possible, (i.e. small gaps) missing values were estimated with linear interpolation. Harmonic analysis on continuous parts of the record revealed a mixed type of tide with similar $N_{f}$ values for the four stations, a result of their locations being close to each other. No co-oscillation phenomena were found within the caldera. Sea level at Taxiarhis station is affected more by atmospheric forcing and shallow water effects in contrast with Gialos station where mean sea level displays significant correlation $(r=0.62)$ with sea surface temperature at lags 2-6 days. The annual cycle of mean sea level (amplitude $=5.74 \mathrm{~cm}$ ) responds to seasonal variations in the thermal structure of the waters, and together with the semiannual cycle explains $9.02 \%$ of the variance in the annual frequency band. Existing data are not sufficiently long to develop a model, which will reconstruct sea level variability resulting from oceanographic and meteorological forcing and will be used for the detection of ground movements from future volcanic eruptions.
\end{abstract}

\section{INTRODUCTION}

In many volcanic areas around the world monitoring networks have been established. Such networks consist of numerous stations and are partly used to predict potential eruptions thus protecting people inhabiting these areas from catastrophic hazards. One of the most important variables recorded is the mean sea level. Abrupt and not predicted variations in water level may result from ground deformation, a precursor of volcanic eruptions (Berrino, 1998). In addition, the identification of low frequency oceanographic and atmospheric phenomena in areas surmounting volcanic islands can be very useful in terms of water level signal decomposition hence providing better estimates for potential eruptions. Many records of sea level data extent back to the 1970's but a number of them contain discontinuous time series since maintaining such networks is not always an easy task. However, even from discontinuous records it is possible to extract some useful conclusions about the effects of oceanographic and atmospheric phenomena superimposing on the recorded signals. This paper focuses on the study of sea level fluctuations and their relation with sea surface temperature at annual time scales in Santorini Island, Southern Aegean Sea. Even though the data set contains numerous and large gaps, useful conclusions are drawn.

\section{STUDY AREA \& DATA COLLECTION}

The volcanic island complex of Santorini is located on the southern part of the Aegean Sea and consists of the islands Thera $\left(76 \mathrm{~km}^{2}\right)$, Therasia $\left(9 \mathrm{~km}^{2}\right)$ and Aspronisi $\left(0.1 \mathrm{~km}^{2}\right)$. These islands en- 
close a sea-filled caldera of approximately $60 \mathrm{~km}^{3}$ as well as the two young volcanic islands of Palaia and Nea Kameni $\left(0.5\right.$ and $\left.3.4 \mathrm{~km}^{2}\right)$. Santorini Island comprises part of the Hellenic Volcanic Arc formed by the subduction of the African plate under the Aegean plate. Volcanic activity began about 2 million years ago and up to today twelve eruptions have been recognised. The present-day caldera is a composite structure created by at least 4 major collapses.

Santorini volcanism is characterized as acidic and has given birth to tremendous eruptions as the well-known Minoan Eruption, which occurred 1640 BC and is responsible for the extinction of the Minoan Civilization. During more recent years smaller eruptions resulted in the formation of Nea and Palaia Kameni islands located in the caldera.

Data used for this study were obtained from R.E.MO.S. (Remote Environmental Monitoring System, Albanakis et al., 1996) network, operated by the Department of Physical and Environmental Geography of the Aristotle University of Thessaloniki and the Institute of Study and Monitoring of Santorini Island. The network consists of 4 stations (Figure 1) two of which are located on the Palaia Kameni island, one on the Nea Kameni island and one on the caldera of Santorini, also used as the reference station. Variables used for this study include mean sea level and sea surface temperature. The dataset spans 36 months of measurements (from $18^{\text {th }}$ October 2000 to $2^{\text {nd }}$ October 2003) with considerable gaps (Figure 2).

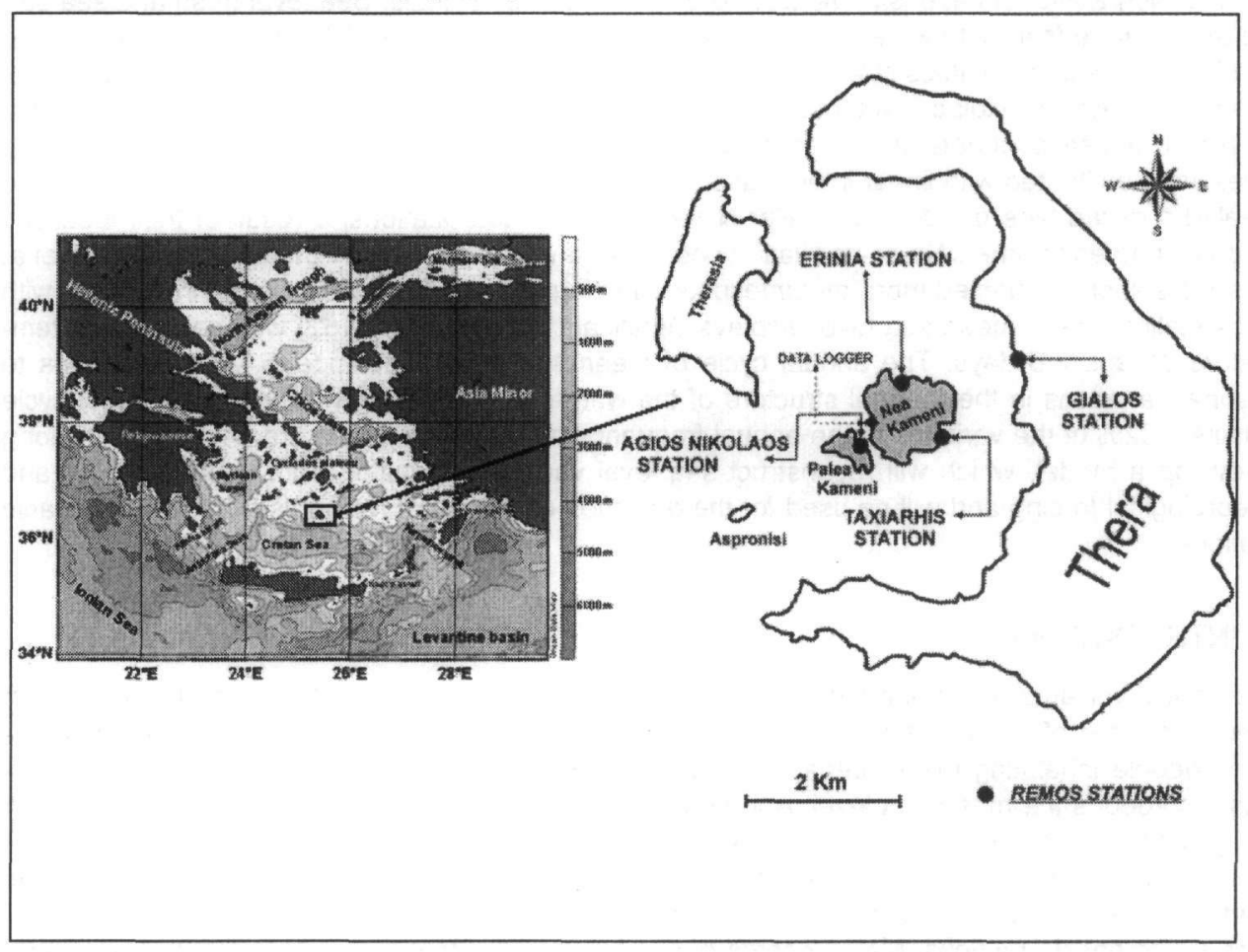

Figure 1. Location of the study area and the REMOS network.

\section{ANALYSIS OF MEAN SEA LEVEL (MSL)}

Mean water levels signal for each station are considered to have various components. Depending upon the location and the underwater topography of each station, observed sea level depends on primary (annual cycles, thermal expansion of the waters, coastal currents) and secondary (long and cross shore wind stress, barometric pressure) forcing (Truccolo et al., 2002). In the time domain, annual and semiannual components as well as long-term linear trends may have significant 
effect on the observed signal. In our case an important factor to be distinguished is the ground deformation resulting from thermal expansion of the crust. This can be presented in the form:

$$
\text { Mean Sea Level }=x(t)+S_{a}+S_{s a}+a(t)+P+\tau_{y}+\tau_{x}+g d
$$

Where $x(t)$, is the predicted tide, $S_{a}$ and $S_{s a}$ are the annual and semi-annual components mainly affected by the sea surface temperature and coastal circulation, $a(t)$ is the long term trend, $P$ is the barometric pressure, $\tau_{y}$ and $\tau_{x}$ are the long and cross-shore wind components and gd is potential ground deformation from volcanic activity.

Subsequent data analyses initially focus on the harmonic analysis of tides as discussed in Pawlowicz et al., 2002 and the estimation of Nf parameter. Removal of linear trends and the use of lowpass band filter allow the comparison of non-tidal signal between all stations. In addition, potential effects of oceanographic and atmospheric forcing on isolated parts of the record are examined.
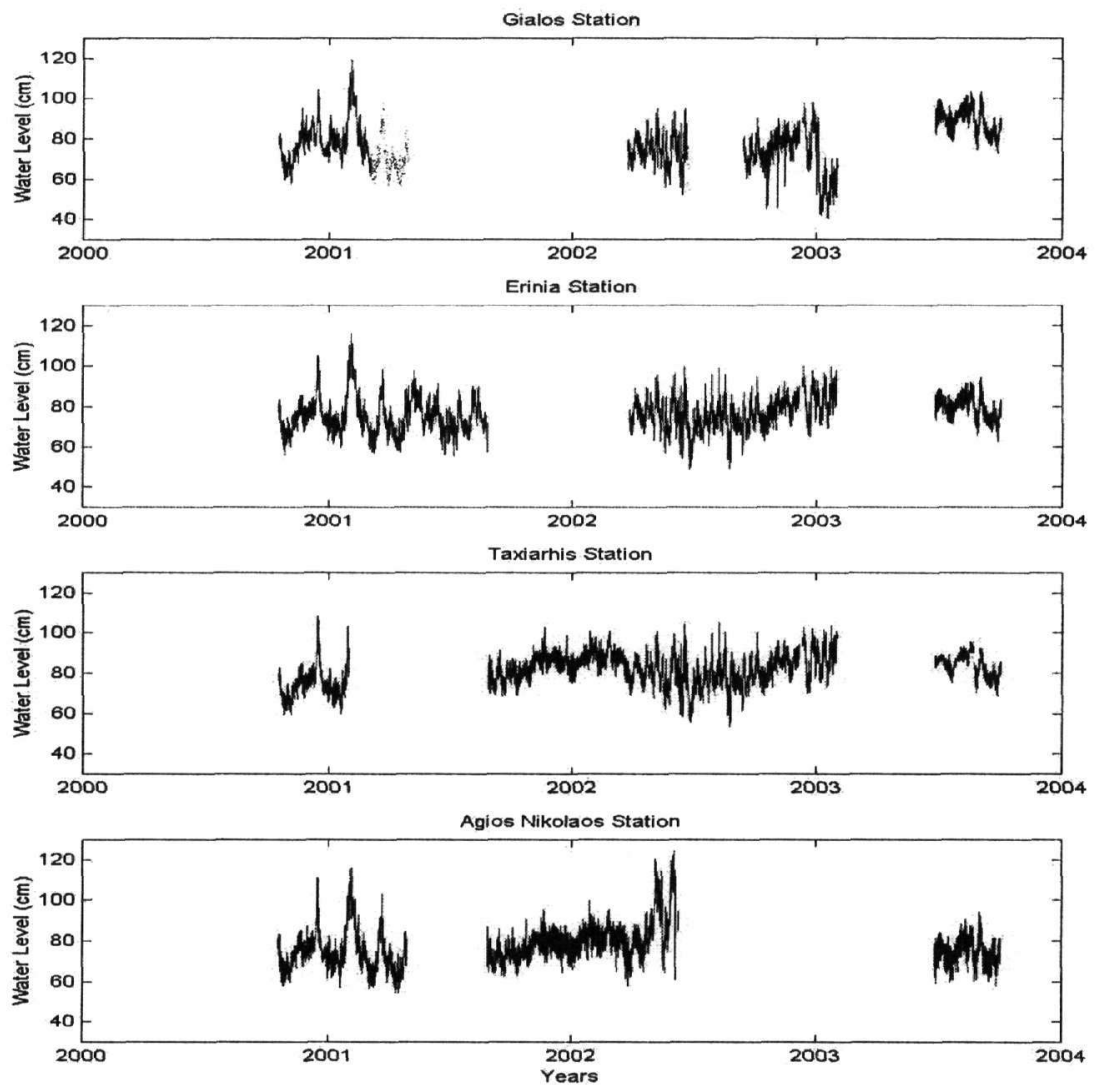

Figure 2. Mean sea level data from all stations of REMOS network

Tidal signals for periods less than 33 hours were removed from the record by using a low-pass filter (cutoff point at 33 hours) decimated to 1-hour intervals. Sea level anomaly was then calculated by subtracting the daily nean instead of the mean of the entire record so that diurnal cycles could be eliminated. The temporal variation is not identical for the four stations as illustrated in Figure 3. The dependence between the four stations in terms of cross-correlation coefficients is illustrated in Table 1. 
Table 1. Cross correlation coefficients between all stations for 72 days of record.

\begin{tabular}{lllll}
\hline \multicolumn{1}{c}{$\boldsymbol{r}$} & Gialos & Erinia & Taxiarhis & Ag Nikolaos \\
\hline Gialos & 1.0000 & 0.8342 & 0.8325 & 0.8278 \\
Erinia & 0.8342 & 1.0000 & 0.9980 & 0.9963 \\
Taxiarhis & 0.8325 & 0.9980 & 1.0000 & 0.9967 \\
Ag Nikolaos & 0.8278 & 0.9963 & 0.9967 & 1.0000 \\
\hline
\end{tabular}

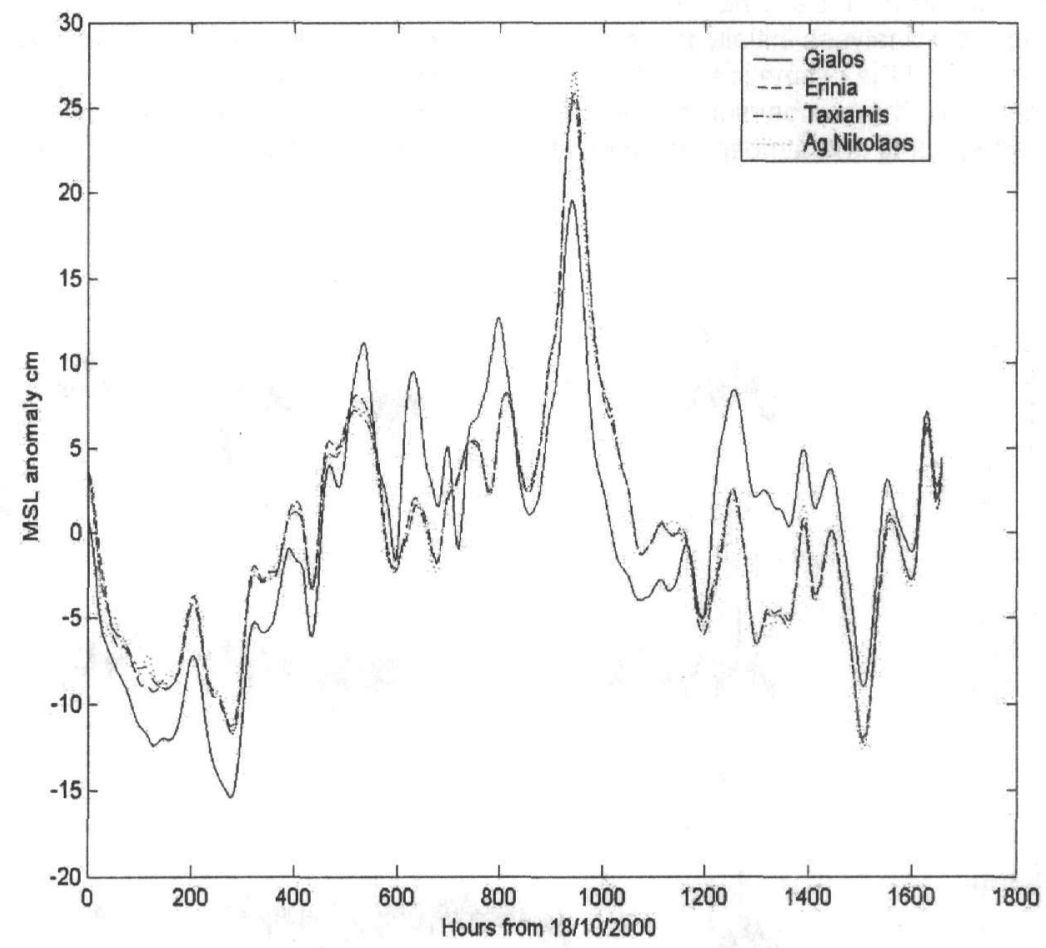

Figure 3. The mean sea level anomaly signal from all stations for 72 days of record (from 18/10/2000 and $30 / 12 / 2000$ ).

Variations in MSL between stations arise from their different locations and oceanographic conditions. In general, stations located in closed embayments are expected to be influenced by non linear shallow water effects, set up of the mean tide and water density variability (Bell and Goring, 1998). The underwater morphology between the four stations is different. Close to Gialos station depths increase abruptlv approaching values of $600 \mathrm{~m}$ very close to the coast, whereas the remaining three are located in shallow water embayments. In particular, Agios Nikolaos station has been installed in the narrow and shallow channel between Palaia and Nea Kameni islands. Potential model development as presented in equation 1, should take into account the effects resulting from different locations so similar equations should be developed for each station. Of great notice are the factors affecting Gialos station sea levels since all villages and resorts are located on the caldera. From the values of Table 1 it becomes apparent that Gialos station is affected by different forcing mechanisms than the remaining stations whose signals are almost identical.

\subsection{Tides and relations between stations}

In order to define the relative roles of tides on the observed signal harmonic analysis was carried out for 72 days of data (from 18/10/2000 to 30/12/2000) to estimate tidal constituents and 
characterize the tides at all stations. The results shown in Table 2, suggest a mixed type of tide mainly semidiurnal for $\tilde{c}_{1}$ stations. Predicted tide variance resulted form the synthesis of the harmonics ranged between $91.94 \%$ for Erinia station to $94.6 \%$ for Gialos station for the period discussed above (and for $95 \%$ confidence limits). No linear trends were identified along this segment of record.

Table 2. Values of $\mathrm{Nf}$ and of the main tidal constituents

\begin{tabular}{ccccc}
\hline $\begin{array}{c}\text { Tidal } \\
\text { constituents }\end{array}$ & Gialos & Erinia & Taxiarhis & $\begin{array}{c}\text { Agios } \\
\text { Nikolaos }\end{array}$ \\
\hline $\mathrm{M}_{2}$ & 1.4669 & 1.6998 & 1.6452 & 1.6067 \\
$\mathrm{~S}_{2}$ & 0.9261 & 1.1158 & 1.0945 & 1.0612 \\
$\mathrm{~K}_{1}$ & 1.6013 & 1.9994 & 1.9450 & 1.8790 \\
$\mathrm{O}_{1}$ & 0.8009 & 0.9291 & 0.9506 & 0.9366 \\
$\mathrm{Nf}$ & $\mathbf{1 . 0 0 3}$ & $\mathbf{1 . 0 4 0 1}$ & $\mathbf{1 . 0 5 6 9}$ & $\mathbf{1 . 0 5 5 4}$ \\
\hline
\end{tabular}

The coastal configuration of the Santorini Island is such that is considered as a semi-enclosed bay. In such embayments tidal co-oscillation phenomena are often observed superimposing on the recorded sea level. Similar effects do not exist mainly because of the great depths and the relative small caldera dimensions (co-oscillation periods ranged between 15 and 40 minutes for different depths). Thus, sea leve, at Gialos is affected by both oceanographic circulation and atmospheric forcing in contrast with the remaining stations where atmospheric factors together with non-linear shallow water effects and set up of the mean tide make up for most of the sea level variability.

\subsection{Seasonal cycle in $\mathrm{msl}$}

Even though there exist major gaps in our records we have selected the longest continuous part to obtain some estimates about the sea level variability on annual and semi annual time scales and also attempt to define c'. her low frequency cycles. Such continuous data have been derived from Taxiarhis station (Figure 2) and cover a period of approximately 18 months (from $23^{\text {rd }}$ of May 2001 to $11^{\text {th }}$ of September 2002). However, some data are still missing from this part of the record but gaps ranged from 2 to 8 hours. These gaps were filled by using linear interpolation techniques. The results of the harmonic analysis for 453 days of sea level data suggest that tides explain only $64.70 \%$ of the original signal variance; the remaining attributed factors described in equation 1 . Of particular interest is the decrease in the explained variance when compared with shorter parts of the record. Harmonic analysis of the Taxiarhis station data explained $93.6 \%$ of the raw signal variance for 72 days, while it dropped to $64.7 \%$ for 453 days of record. This suggests that low frequency forcing become: more important at semiannual and annual time scales. Data manipulation is similar to that discussed above, with the removal of linear trends and daily means and the use of 33 hour pass band filter.

The seasonal cycle for the Taxiarhis station was derived by the annual and semi-annual harmonics. Analyses results suggest that the annual harmonic $S_{A}$ has an average amplitude of $5.74 \pm$ $2.6 \mathrm{~cm}$ and accounted for $8.2 \%$ of the variance at the $95 \%$ significance level. This is translated in the seasonal sea level peak occurring during September. In addition, the semi-annual $S_{S A}$ harmonic amplitude was $2.5 \pm 2.1 \mathrm{~cm}$ corresponding to two highs, one during September - October and the other one during March - April (Figure 4). Semi-annual harmonic accounted for a mere $0.9 \%$ of the sea level variance. Of $p: t$ ticular importance is the increased signal water level variability during the winter season (November - April), which is probably related to atmospheric disturbances.

In order to get more insight about other forcing mechanisms spectral analysis was carried out on the remaining signal. The resulted sea level spectra revealed peaks at 120, 24 and 13 days in agreement with the periods of intra-annual harmonics. The 120 -day (1/3 year) spectral peak likely corresponds to large-scale meteorological forcing within the Mediterranean basin (Shirman \& Mezler, 2002), while the 24 and 13 day peaks are probably a result of atmospheric forcing being similar to the period of major storms in Southern Aegean Sea (Poulos et al., 1997). 


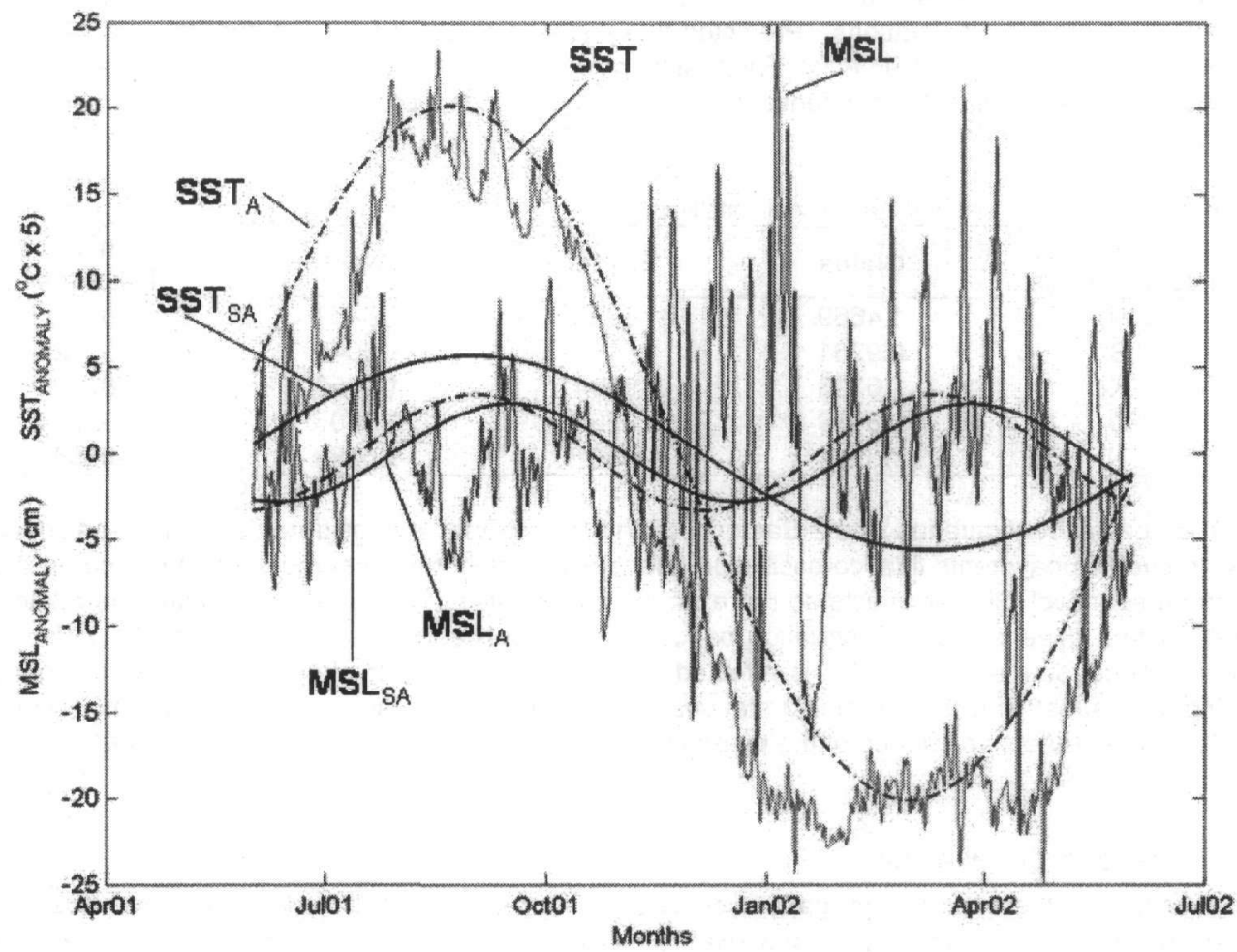

Figure 4. Taxiarhis station anomalies of MSL and SST with the correspondent annual $\left(M_{S} L_{A}, S_{S T}\right)$ and semiannual harmonics (MSLSA, SST SA).

\subsection{Seasonal cycle in sst}

The seasonal variation of coastal waters temperature is an important forcing variable in temperate latitudes, and produces seasonal sea-level fluctuations (Pattullo et.al., 1955). To compare with MSL anomaly Figure 4 displays the MSL and SST anomalies together with the annual and semiannual harmonics. From figure 4 it becomes apparent that SST annual and semi-annual harmonics precede the MSL ones by 9 and 27 days, suggesting that SST has an effect on MSL on seasonal time scales. Such results are consistent with other studies (Bell and Goring, 1998, Pattullo et al., 1955) where thermal-steric effects are found to explain most of the seasonal variation in MSL. The annual SST harmonic aiiplitude is $4.28{ }^{\circ} \mathrm{C}$, while the semi-annual harmonic amplitude is $0.67{ }^{\circ} \mathrm{C}$. Annual SST harmonic explains $95.13 \%$ of the SST in contrast with the variance explained by the annual MSL harmonic a value of $8.2 \%$. Thus meteorological forcing and other non-linear effects are thought to have an important role on the sea level since they cause departures from classic sinusoidal response.

In contrast to MSL, SST displays less variability during the winter season (November - April) when water temperature values are closer to those of the permanent thermocline for the Aegean Sea (Poulos et al., 1997).

A linear trend in the order of $1.52^{\circ} \mathrm{C}$ was found in the SST signal and was then removed together with the annual ind semi-annual harmonics, so that we attempted to correlate MSL and SST. Cross correlation coefficients between MSL and SST were found to be insignificant at the $95 \%$ confidence level probably because the MSL signal is greatly affected by meteorological factors. It appears that Taxiarhis station location prohibits oceanographic factors to force sea levels since the swallow embayment filters effects as thermal expansion of the sea. 
In contrast, Gialos station is more prone to oceanographic for̀cing due to its proximity to deepwater circulation. A high correlation is observed between SST and MSL for the 72 days of record. Correlation becomes higher $(r=0.62)$ at lags $3-6$ days SST preceding MSL. This intra-annual relation results from deep-water circulation within the caldera explaining also the difference between Gialos and the other three stations as shown graphically in Figure 2.

\section{DISCUSSION}

The study of sea level variations at four stations around Santorini Island revealed that different factors affect each location. At stations on the Palaia Kameni Island there is no correlation between MSL and SST, a result of the fact that the stations have been installed in semi-closed embayments. Annual MSL harmonic lagged the SST one by about 9 days. In contrast, at Gialos station sea level fluctuations are driven by SST, a result of oceanographic circulation patterns. Unfortunately meteorological forcing cannot be assessed with the existing REMOS data in Santorini Island. Besides MSL and SST other variables such as barometric pressure and wind stress and direction should be included. Such data $\mathrm{CE}^{-}$- be obtained either from the literature or from large-scale atmospheric models but this is subject for future work. These factors should be considered for future model development, which will account for atmospheric, oceanographic forcing and other effects will for each station will be a useful tool for predicting ground deformation signals on the sea level data.

\section{REFERENCES}

Albanakis, K., Laopoulos Th. \& Kosmatopoulos C., 1996. Sea-level monitoring network of Santorini volcanic islands, 2nd Workshop c'. European Laboratory Volcanoes, Santorini, Greece.

Bell, R.G., \& Goring D.G., 1998. Seasonal Variability of Sea Level and Sea Surface Temperature on the North east Coast of New Zealand, Estuarine Coastal and Shelf Science, 46, 307-318.

Berrino, G., Corrado, G. \& Riccardi, U., 1998. Sea gravity data in the Gulf of Naples: a contribution to delineating the structural pattern of the Vesuvian area, Journal of Geophysical Research, 82, 139-150.

Pattullo, J., Munk, W., Revelle, R. \& Strong E. 1955. The seasonal oscillation in sea level. Journal of Marine Research 14, 88-155.

Pawlowicz, R., Beardsley ť.., \& Lentz S., 2002, Classical Tidal Harmonic Analysis Including Error Estimates in MATLAB using T_TIDE, Computers and Geosciences.

Poulos S.E., Drakopoulos P.G. \& Collins M.B., 1997, Seasonal Variability in Sea Surface Oceanographic Conditions in the Aegean Sea (Eastern Mediterranean): An Overview, Journal of Marine Systems, 13, 225-244.

Shirman B., \& Mezler Y., 2002, Mediterranean Sea Level changes over the period 1961-2000.XXII International Congress, Washington D.C., USA.

Truccolo E. C., Franco D. \& Schettini C., 2002, Coastal Sea Level Variability Due to Meteorological Forcing in the Northern Coast of Santa Catarina, Brazil: Predictions, Littoral 2002, The Changing Coast, EUROCOAST I EUCC Porto, Portugal. 